\title{
The Function of Transference Interpretations in Klenian Therapy
}

Deniz Coşan*

Psychodynamic Psychotherapy, Mia Medina, Teşvikiye Mah, HacıEmin Efendi Sk, Istanbul

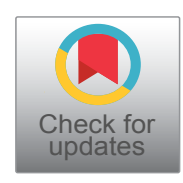

*Corresponding author: Deniz Coşan, Psy D, Psychodynamic Psychotherapy, Mia Medina, Teşvikiye Mah, HacıEmin Efendi Sk, 72/11 Şişli, İstanbul, Tel: 0090-538-811-4080

\begin{abstract}
In this paper, the function of transference interpretation in Kleinian therapy is evaluated. In the beginning, definition of transference and transference interpretation is given in general terms. The term of transference refers to attributed emotions, attitudes, and phantasies from past towards a person in the present that are inappropriate for that person. Transference interpretations aim to reveal inappropriate attributions towards the therapist made by the patient. The term of transference offered with more rigorous and detailed definition in Kleinian theory, and transference is perceived as more inclusive. It is perceived as it starts from the beginning of therapy. As transference gains more importance in Kleinian therapy, transference interpretations become vital as well. Klein's theory is based on object relations school and, thus, that the understanding of transference includes internalized objects. In Kleinian understanding, transference and transference interpretations takes place in the center of therapeutic work. Negative transference interpretations are significant as they enable the patient turn to the therapist. Additionally, as it is believed that all mental states carry the transferetial material, therapy is evaluated in the terms of the total situation. Total situation refers to all material in analytic work, both conscious associations and unconscious projections are valuable for understanding the transference, therefore, all analytic materials might be used for transference interpretations. Contemporary Kleinian therapists emphasized the importance of immediate 'here and now' interpretations.
\end{abstract}

\section{Introduction}

In this paper, Klein's contribution to the term transference and Klenian theory and practice of transference interpretation is discussed. For this reason, transference reactions and transference interpretation is defined in general terms in the beginning. Then, Klenian theory is introduced very briefly. After that, highlighted points on transference and transference interpretations in Klenian therapy are investigated in details: Transference reactions as externalization of unconscious phantasy, emphasis on negative transference, the total therapeutic situation as a transferential material, interpretation of projective identification and part-objects in the transference. In conclusion, a general view of Klenian therapy is drawn and contemporary Klenian technique is mentioned.

\section{Transference Reactions}

The first time, transference became an issue in psychoanalysis was with Dora case of Sigmund Freud [1]. Then, it is believed that transference reactions bring out the vital materials of psychoanalytic work. Transference reactions supplies the essential information about repressed past experiences of the patient [2].

Transference is the experiencing of feelings, drives, attitudes, fantasies, and defenses toward a person in the present which are inappropriate to that person and are a repetition, a displacement of reactions originating in regard to significant persons of early childhood [2].

The transferred material does not have to reflect the reality. As an example of transference reaction, Habip [3] mentions about her patient who transferred the rash and impatient aspect of her mother to Habip as her therapist, and talks very rapidly without noticing important points of her story such as the death of her father. Habip soon realized that the patient was not the rash and rapid one but Habip was as a transference figure. 
Psychoanalytic therapy is the sole psychotherapy type that uses transference reactions to work on the therapeutic relationship as a treatment material [2]. Transference reaction is a form of resistance as it is to repress memory and to repeat the experiences in acting out defenses. Transference reactions are evaluated under two categories: Positive transferences and negative transferences.

Positive transference refers to the different forms of sexual longing as well as liking, loving, and respecting the analyst. The negative transference implies some variety of aggression in the shape of anger, dislike, hate or contempt toward the analyst [2].

\section{Transference Interpretation}

Transference reactions are only meaningful to therapeutic work if they are interpreted by the therapist. Interpretation of the transference refers to the clarification and verification of transference reactions communicated to the patient. Conveying transference interpretation to the patient is only possible by working with the involvement of observing ego while giving meaning to acting outs of experiencing ego [4]. Thus, the transference interpretation is limited to the patient's observing ego's comprehension at that time. Additionally, in order to reach effectiveness in transference interpretation for working through analytic material, constant repetition is significant, as that is the sole technique to analyze and overcome transference resistances [2].

\section{Kleinian Therapy and Object Relations Approach}

The type of psychotherapy based on Melaine Klein's work, assumptions and formulations is called 'Kleinian therapy' [5]. In the beginning of her work, she defined herself as a faitful follower of Freud [5]. However, her approach was differentiated from Freud's, as Freud takes into account the conflicts of drives and the conflict of ego, superego and id in the internal world, where Klein's theory is depended upon the internal world of objects such as parents and significant others. Considering the understanding of internal world of Klein, she belongs to the object relations school. According the object relations theory, the basic need of human being is to relate, and the main motivating force is to get involved in relationships [6].

Klein's theories are mainly based on her psychoanalytic work with children. She regarded play technique with children as the parallel of free association technique in adults, and her work with adults was also relied on the child in adult patients.

The Perception of Transference in Kleinian Therapy

She contributed to the term of transference by focusing attention on negative transference and approaching all therapeutic situations and all associations as related to the transference-that is called the total situation [7]. Klein's notion of transference is much more detailed, strict and inclusive:

I found that with children the transference (positive or negative) is active from the beginning of analysis, since for instance even an attitude of indifference cloaks anxiety and hostility. With adults too I found that the transference situation is present from the start in one way or another, and I have come, therefore, to make us of transference interpretations early in analysis [8].

According to Kleinian approach, transference is not developed over time as it was believed earlier. In Kleinian work, transference interpretations should start from the beginning of therapeutic work as it is believed that transference reactions in therapy start from the beginning. Segal claims that "emphasis on the importance of transference interpretations is one of the distinctive features of Kleinian approach" (pp.69) [9].

Klein suggests that every single session should include transference interpretation. In Kleinian way of transference interpretation, the therapist should discover the feelings of the patient towards the therapist, and speaks of those in the name of feelings towards the original objects [10]. That kind of transference interpretation was the notable innovation in Kleinian therapy, and neverthelessit is not followed by every therapists [9].

Klein (1975) encouraged the therapist enabling his patient elaborating on what he told, and then making the interpretation on the experiences, emotions and attitudes as they are related to the relationship with the therapist by offering the similarity between the perception of the therapist and original objects [10].

\section{Transference Reactions as Externalization of Unconscious Phantasy}

Transference reactions in orthodox psychoanalysis are seen as repetition of old traumas, events, emotions and attitudes from the past of patient. However, according to Kleinian theory, transference reactions are not only those simply but they are the externalization of unconscious phantasy in the therapy room towards the therapist. Hinshelwood defines unconscious phantasy as underlying under every mental process and involving in all psychological reactions, and phantasy as referring to mental representations of both innate needs and defenses against innate needs [7]. Kleinian theory asserts that unconscious phantasy is projected on the therapist as a transference reaction in the "here and now' situation [7].

Klein was able to grasp that enactments in the therapeutic setting does not have to come from the past memories but they may be related to current 
experiences and relationships. She worked with children, sometimes, as young as two-year-olds. They were bringing their all kind of current happenings and their phantasy life to the therapy in order to encompass their traumatic experiences of daily life. In adult psychotherapy, this new kind of information is used to form the term transference as it is to bring current phantasy experiences to therapy [7].

Strachey extended the view of 'here and now' comprehension of transference in the way that as the therapist interprets the unconscious motives and desires towards the experiences that are out of the therapy room, the direction of emotions, desires, motives and phantasies would change towards the therapist as the patient hears the interpretation [11]. For instance, as the therapist mentions about an unconscious desire of a patient's to kill his father, the patient would feel angry, suspicious, maybe grateful and many more emotions towards the therapist.

\section{Klein's Emphasis on Negative Transference}

The feelings of aggression and destructiveness are brought to the therapy room by the patient in the name of negative transference towards the therapist. Such importance of negative transference, the vitality of interpreting conflicts immediately in the therapeutic relationship, is understood with the works of schizophrenics in 1940s [7]. Hatred and rivalry bringing by the patient is not solely towards the parents but also towards the therapist both in child and adult patients. The transference interpretation would be effective if they are regarded as consisting of both positive and negative feelings. Klein criticized Anna Freud for leaving negative feelings outside the work with children, thus, Anna Freud as a therapist collects all the positive feelings and leaves the negative ones for the parents [10]. However, if the patient's analytic material is worked through including both positive and negative emotions, phantasies and attitudes in the transference towards the therapist, the patient's relationship with both the therapist and people from the outer world would be improved.

\section{The Total Situation as Transferential Material}

The total situation could be explained in two ways. First, transference covers all positive and negative aspects, not only the positive ones [7], therefore, transference interpretations would be effective only when transference reactions are perceived as a whole. Secondly, it is far more different than it is previously considered, Klein regarded all materials in the therapeutic setting as a transference issue [12]. "It must include everything that the patient brings into the relationship (pp.447).... The patient's immediate anxieties and the nature of her relationship with her internal figures emerge in the whole situation lived out in the transference" [12]. Not only the ones simply directed at the therapist but all kind of memories, phantasies, conflicts, daily life issues are needed to be evaluated as a transference material towards the therapist. Whenever solely regarded the explicitly directed explanations towards therapist as transference material, the therapist misses so much information could be regarded as transference material [12]. Any detail including relationships with friends, the emotions towards a loved one, conflicts in outer world, and phantasies towards a partner are necessary to be taken into account as emotions, conflicts and phantasies towards the therapist. Riviere interpreted this feature of transference as that the unconscious material is in the conscious material [13]. Conscious stories are representations of unconscious anxiety provoked in the transference situation [12].

Klein claims that the patient would be in the effort of splitting the therapist figure as good or bad, and project the other side -if the therapist is perceived as a good figure the negative side, and if the therapist is perceived as a bad figure the positive emotions, thoughts and attitudes- to the people in the outer world, which is part of 'acting out' process. Regarding analytic material as a whole and by interpretation bringing together all positive and negative aspects in one transference figure, the therapist, would enable the patient to regard his inner world as whole. The integrating function of this kind of transference interpretation demonstrates the importance of the total situation [7].

\section{Transference Interpretations of Projective Identification}

Internalized object relations are not only transferred through using words to communicate, but also acted out in the transference situation with projection. The therapist feels in a certain way as a result of projective identification:

Projective identification was defined by Klein in 1946 as the prototype of the aggressive object-relationship, representing an anal attack on an object by means of forcing parts of the ego into it in order to take over its contents or to control it and occurring in the paranoidschizoid position from birth. It is a 'phantasy remote from consciousness' that entails a belief in certain aspects of the self being located elsewehere, with a consequent depletion and weakened sense of self and identity, to the extent of depersonalization; profound feelings of being lost or a sense of imprisonment may result [7].

For instance of projective identification experience, Joseph mentioned about a patient's therapy story brought to a seminar, where participants of the seminar felt it was so hard to understand more about the patient [12]. However, that was the countertransference reaction of the therapist and the situation was reenactment of the uncomprehending mother and the 
non-understood child. By considering the example, transference interpretation that are made only by taking the individual associations into account would be inadequate as they are able to connect and reflect merely the adult part of the patient's personality. However, more infantile parts of personality would be only understood by evaluating, perceiving and interpreting the pressures on the therapist those are the cause of projective identification.

The infantile perception consists of nonverbal characteristics, occurs before the child verbally grasps the world, and therefore, it is hard to define in words what is happening both in the patient and in the therapist as a consequence of projective identification.

Freud mentioned about 'projection' as attribution of one's impulses to someone else [7]. Klein's definition of the term 'projection' differed from Freud's as she suggested that the projection of impulses were not possible without the projection of ego parts [14]. Bion explained 'projective identification' as playing a part in someone's phantasy and extended the definition further by defining normal and pathological projective identification. Normal projective identification is "to introduce into the object a state of mind, as a means of communicating with it about this mental state" [7], whereas pathological one is "to evacuate violently a painful state of mind leading to forcibly entering an object, in phantasy, for immediate relief, and often with the aim of an intimidating control of the object" (pp.184). It might be considered that the pathological projective identification would be more challenging, more demanding, harder to grasp, experience and put into the words. Without reaching the suitable words to explain the identified role, it would be tough to interpret the projective identification. However, once it is understood, interpreted, and delivered in words correctly, and it is crucial not to forget that the interpretation would be constantly and repeatedly, the lightening of patient, relief of anxiety and improvement in therapy would be possible.

\section{Part-Objects in the Transference}

As Klein figured out the nature of splitting objects, her understanding, theory and technique of transference interpretations developed. Following the sequence of free association of the patient gives clue to perceive the splintered fragments of the relationship built with the therapist [7].

The nature of splitting object based on the experiences as an infant before verbal self is occurred. The infant grasps different aspects of mother as separate objects. The integration of separate parts in the same object would occur in the later years of development. Feeding, cleaning, and fondling mother are grasped as separate objects, thus, they are internalized separately. Additionally, the good and bad aspects of the mother are also internalized as they are separate objects. The good mother has the positive features of caring, feeding and fulfilling needs on time, and the bad mother has negative features such as not being able to meet needs on time. Before integration of objects are possibly made, the perception of a single object is partial, therefore, transference of infantile experiences towards the therapist are partial, and thus, it consists of part-objects.

Transference reactions include both the integrative objects from present and past, and the part-objects internalized in the early days of development. This feature of transference demonstrates that it being multi-layered. As making transference interpretations, it is crucial to consider this multi-layered feature of transference as it consists of both integrated and partial objects, and it is necessary to interpret all layers of transference.

Innovative understanding of transference including part-objects enabled the psychotic patients to be analyzed, even though Freud believed that psychotic patients were unanalyzable because he was not able to grasp the nature of transference with split aspects until the work of Klein in 1946 [7].

\section{Therapeutic Effects}

Klein did not only offered several theoretical background but she also demonstrated that her theories are effective in practice as she showed case examples of reducing anxiety and changing the relationship between the therapist and the patient in a more positive manner. She stated as "I have again and again seen how rapidly the interpretations take effect".

Klein indicated that transference interpretations might not be understood consciously immediately, however unconscious associations are made and observed as reactions. The patient's reactions are more significant than his conscious responses and conscious statements of agreement with the therapist's interpretations. Conscious awareness might follow the unconscious agreement later in the therapeutic process.

Strachey explains that transference interpretations should reflect the 'here and now' situation and they should be immediate. He also pointed out the mutative nature of transference interpretations [11]. Immediate 'here and now' transference interpretations enable the patient to constitute a more realistic introjection of the therapist with the integration of good and bad parts.

In clinical examples of Klein work, the effectiveness of interpretation of negative transference determined. "Interpretation of the negative transference (hostile feelings), while they were being displayed, had quite astonishing results which enabled the child to turn immediately to the analyst" [7]. However, Klein was against making wild interpretations without evidence of 
any link to play of the child nor the free association of the adult patient. Klein stated that she always had an evidence for transference interpretation [7].

Malcom identified that transference interpretations refer to interpret past and present concurrently, and therapeutic improvement can be only supplied by interpreting the patient's relationship to the therapist. Malcom added that interpretation of the patient's past is not the aim of the therapy, however it might be used to enable the patient grasping the continuity of his life. The interpretation should include the immediate relationship of the patient and the therapist with its both verbal and nonverbal representations, and this leads us to the importance of projective identification in order to grasp what is happening between the therapist and the patient.

\section{Conclusion}

Klein's contribution to the analytic work is mainly the change of understanding of the term transference and demonstrating the importance of transference interpretations. Earlier, transference was regarded as something that develops in time in the therapeutic process, however Klein objected that by suggesting that the transference in the therapeutic relationship starts in the beginning of the therapy, thus, the transference interpretations might begin even with the first session. Elaboration of the patient's free association is still necessary, nevertheless material brought with free association should be connected to the patient's relationship to the therapist with transference interpretations.

Klein also emphasized the importance of interpretation of negative transference. Klein criticized Anna Freud for leaving the negative aspects of the transference out, and that caused the projection of negative material in the inner world to the outer world outside the therapy room. However, evaluating the negative aspects of inner world in the transference relationship would enable the patient to connect the good and bad sides in order to constitute a more integrative perception of internalized objects.

Klein highlighted the significance of projective identification. It is only possible to understand the patient fully with the help of countertransference experiences resulted from projective identification. Adult part of the patient's characteristic would be conveyed through words, nevertheless internalized infantile emotions, experiences and phantasies before the verbal development of child could be only communicated through projective identification. Klein covered the understanding of projective identification as one of the vital elements in the therapeutic improvement rather than considering it as a resistance to therapeutic change.
According to Kleinian therapy, all therapeutic material could be regarded as transference, which is called the total situation. Therefore, all analytic material could be used for transference interpretation. The stories of the patient should be heard by the therapist accompanying a question of 'What does it tell about me as a therapist and about the relationship between me as the therapist and the patient'. The stories might be seen irrelevant to the therapy such including relationship with a friend, conflict with a lover etc. However, the stories offer the possibilities of the patient's inner world and show that there is no other way to grasp a relationship for that patient, thus, the relationship with the therapist would be grasped in that way told in the stories seen irrelevant. Skipping indirect material to the therapeutic relationship would cause to miss so much important information about the transference.

Transference is multi-layered and it is significant to work through layers of transference. In order to do that resources could be used such as the conscious stories of the patient and the unconscious projective identification process. Layers of transference include part-objects. Part-object refers to the unintegrated aspects of internalized objects. Feeding aspect of the mother, cleaning aspect of the mother, and not fulfilling needs on time aspect of mother internalized as separate objects by the infant. Transference of the patient to the therapist includes all aspects and all part-objects, therefore, the transference interpretation should refer to different part-objects at different times.

\section{Contemporary Klenian Technique}

Contemporary Kleinian therapists emphasizes the 'here and now' situation and the importance of immediate interpretations referring to the "here and now'. They take into account the all aspects of the therapeutic setting. They gave importance to understand the content and meaning of anxiety, to interpret the anxiety rather than the defenses merely. Comprehension of part-objects extended as they were referred to parts such as breast, penis, nipple etc., "Destructiveness began to be interpreted in a more balanced way [7]. The immediate use of part object language tended to be replaced by a more step by step approach to the bodily expressions of unconscious phantasy. The concept of projective identification began to be used more directly in analyzing the transference.... there has been increasing emphasis on acting out in the transference and on pressure being put on the analyst to join in" [14].

\section{References}

1. Freud $S$ (1905) Fragment of an analysis of a case of hysteria (1905 [1901]). Standard Edition 7: 3-122.

2. Greenson RR (1994) The technique and practice of psychoanalysis. London: The Hogarth Press.

3. Habip B (1997) Psikanaliziniçinden İstanbul: YKY. 
4. Bibring GL (1954) The training analysis and its place in psycho-analytic training. Int J Psycho-Anal 35: 169-173.

5. Britton R (2012) Klein and Bion In: GO Gabbard, EL Litowitz, P Williams. Textbook of psychoanalysis (2 ${ }^{\text {nd }}$ edn) Washington, DC: American Psychiatric Publishing.

6. Williams P (2012) Object relations In: GO Gabbard, EL Litowitz, P Williams. Textbook of psychoanalysis. ( $\left.2^{\text {nd }} \mathrm{edn}\right)$, Washington, DC: American Psychiatric Publishing.

7. Hinshelwood RD (1991) A dictionary of Klenian thought. London: Free Association Book.

8. Klein M (1943) Memorandum on technique. In: RD Hinshelwood (1991). A dictionary of Klenian thought. London: Free Association Book.

9. Segal J (2004) Melanie Klein. London: Sage Publications.
10. Klein M (1975) The psychological foundations of child analysis. In Psychoanalysis of children. London: The Hogarth Press. (First published in 1932).

11. Stracthey J (1934) The nature of the therapeutic action of psycho-analysis. Int J Psycho-Anal 15: 127-159.

12. Joseph B (1985) Transference: The total situation. In: Melanie Klein today: Developments in theory and practice. London: Routledge 2.

13. Riviere J (1952) General introduction. In: M Klein, P Heimann, S Isaacs, J Riviere, Developments in psychoanalysis. London: Karnac Books.

14. Spillius EB (1983) Some developments from the work of Melanie Klein. Int J Psychoanal 64: 321-332. 